\title{
An Experimental Study of Variable
}

\section{Compression Ratio Engine Using Diesel Blend - A Computing Approach}

\author{
S. Vinodh ${ }^{1}$, A. Bragadeesh ${ }^{2}$, P. Nishanth ${ }^{3}$ \\ ${ }^{1}$ Assistant professor, Department of Aeronautical, Mahendra Engineering College, Namakkal, India \\ ${ }^{2,3}$ Student, Department of Aeronautical, Mahendra Engineering College, Namakkal, India
}

\begin{abstract}
Increase in the scarcity of the fossil fuels, prices and global warming have generated an interest in developing alternate fuel for engine. Technologies now focusing on development of plant based fuel, plant oils and plant fats as alternative fuel. The present work deals with finding the better compression ratio for the honne oil diesel blend fueled C.I engine at variable load and constant speed operation. In order to find out optimum compression ratio, experiments are carried out on a single cylinder four stroke variable compression ratio diesel engine. Engine performance tests are carried out at different compression ratio values. The optimum compression ratio that gives better engine performance is found from the experimental results. Using experimental data Artificial Neural Network (ANN) model was developed and the values were predicted using ANN. Finally the predicted values were validated with the experimentally.
\end{abstract}

Keywords- biofuel, ANN, feed forward back propagation, variable compression ratio diesel engine, optimization.

\section{INTRODUCTION}

Predicting and analysis of chemical reactions of fuels are important tasks because they can unlock insights into the complicated dynamics of systems which are difficult or expensive to test experimentally. Optimisation of the compression ratio of diesel fuelled with variable compression ratio C.I engine at various compression ratios and concluded that at compression ratio 14.8 improvements in performance and emission characteristics were attained [9]. Investigation of the performance and emission parameters of methyl ester of cottonseed oil blended with diesel in a single cylinder variable compression ratio diesel engine at a constant speed of 1500rpm and concluded that the highest brake thermal efficiency and lowest specific fuel consumption were observed for 5\% biodiesel blend for compression ratio of 15 and 17 and $20 \%$ biodiesel blend for compression ratio of 19 and also the maximum $\mathrm{NO}_{\mathrm{x}}$ emission were observed for
$20 \%$ biodiesel blend at a compression ratio of 17 and also observed $\mathrm{CO}$ emissions and smoke in the full range of compression ratio and loads [8]. The Variable Compression Ratio SI engine performance and emission using pure petrol, pure LPG, Ethanol blends and kerosene blends and observed that the LPG is a promising fuel at all loads lesser carbon monoxide emission compared with other fuels tested and also found that petrol mixed with ethanol at $10 \%$ by volume is better at all loads and compression ratios [8]. Investigation of the performance parameters and exhaust emission parameters using different percentage of blends of Honne oil with diesel at various compression ratios. The experimental results were used to train the Artificial Neural Networks (ANNs) which is used to predict the Engine performance and emission characteristics of the engine. ANN results shows good correlation between the ANN predicted values and the experimental values for various engine performance values and the exhaust emissions [7]. Investigation of the output parameters of CI engine using diesel and sunflower oil blends and experimentally calculated values can be used for training several neural networks using MATLAB. They calculated the trained error values by comparing the output values given by these trained networks with experimental values. The Maximum percentage error between experimental and theoretical values is 0.1691 and suggested that the ANN can be used as a powerful tool to optimize the input parameters in the C.I engine [3]. Biodiesel (palm oil methyl ester) blends in a direct injection diesel engine study shows that the lower blends of biodiesel increases the brake thermal efficiency, reduces the fuel consumption and produce lower engine emissions than neat diesel [4]. The performance and emission characteristics of neat diesel (ND) and neat honne oil (H100) as fuel in DI diesel engine and result shows, at maximum load, brake thermal efficiency and NOx emission decreased whereas emissions like $\mathrm{CO}, \mathrm{HC}$ increased [5]. The performance characteristics of variable compression ratio diesel engine using ethanol blends with diesel [1]. The artificial neural network modelling of a 
diesel engine using nakthamala oil biodiesel fuel to predict the exhaust emissions of C.I.engine. The experimental results reveals that blends of nakthamala oil methyl ester (NOME) provide improved emission characteristics and ANN results showed good correlation between the ANN predicted values and the desired values for various engine exhaust emissions [2].

From the above studies it is clear that biodiesel can be used as an alternate for diesel without modifications in the C. I Engine and ANN can be used as a prediction algorithm to get better correlation with the experimental values.

\section{TRANSESTERIFICATION}

Transestrification if the process of using alcohol(e.g. Methanol, ethanol or butanol),in the presence of a catalyst, such a sodium hydroxide or potassium hydroxide, to break the molecule of the renewable oil chemically into methyl or ethyl ester of the renewable oil, with glycerol as a by product. Biodiesel, defined as the mono-alkyl esters of fatty acids derived from vegetable oil or animal fat, in application ass an extender for combustion in diesel engines, has demonstrated a number of promising characteristics, including reduction of exhaust emissions. Transesterified, renewable oils have proven to be a viable altemative diesel engine fuel with characteristics similar to those of diesel fuel. The transesterification reaction proceeds with or without catalyst by using primary or secondary monohydric aliphatic alcohols having 1-8carbon atoms as follows:

\section{OF A DIESEL ENGINE USING NAKTHAMALA OIL BIODIESEL FUEL TO PREDICT THE EXHAUST EMISSIONS OF C.I. ENGINE.}

Triglycerides + Monohydric alcohol $=$ Glycerine + Mono-alkyl esters.

\section{A. Properties of Calophylluminophyllum oil}

In this present work the calophylluminophyllum oil methyl ester is produced by transesterification process. Transesterification is a chemical reaction between triglyceride and alcohol in the presence of catalyst.Transesterification makes the viscosity lowered.

The purified calophylluminophyllum oil methyl ester was then blended with petroleum diesel in various concentrations for preparing biodiesel blends to be used in $\mathrm{CI}$ engine for conducting experiments. The properties of calophyllum inophylum oil are listed in Table I

\section{Table I: Properties of Calophylluminophyllum oil}

\begin{tabular}{|c|c|c|c|}
\hline Properties & Units & HSD & Honne Oil \\
\hline Density At $30^{\circ} \mathrm{C}$ & $\mathrm{kg} / \mathrm{m}^{3}$ & 830 & 910 \\
\hline Kinematic Viscosity & $\mathrm{mm}^{2} / \mathrm{s}$ & 3.12 & $(32.48 \pm 2)$ \\
\hline
\end{tabular}

\begin{tabular}{|c|c|c|c|}
\hline At $40^{\circ} \mathrm{C}$ & & & \\
\hline Flash Point & ${ }^{\circ} \mathrm{C}$ & 56 & 120 \\
\hline Fire Point & ${ }^{\circ} \mathrm{C}$ & 75 & 160 \\
\hline Pour Point & ${ }^{\circ} \mathrm{C}$ & $(-16 \pm 1)$ & $(-08 \pm 1)$ \\
\hline Heating Value & $\mathrm{kJ} / \mathrm{kg}$ & 43000 & 39100 \\
\hline
\end{tabular}

\section{EXPERIMENTAL INVESTIGATIONS}

Variable compression ratio diesel engine test rig was shown in the Fig.1 and its specifications are given bellow.

Bore in $\mathrm{mm}$

Stroke in $\mathrm{mm}$

Rated speed in rpm $\quad-1500$

Rated power output in KW $\quad-5$

Method of Loading

Compression ratio

Diameter of orifice in $\mathrm{mm}$

Type of ignition

Method of starting

Method of cooling

No of cylinder

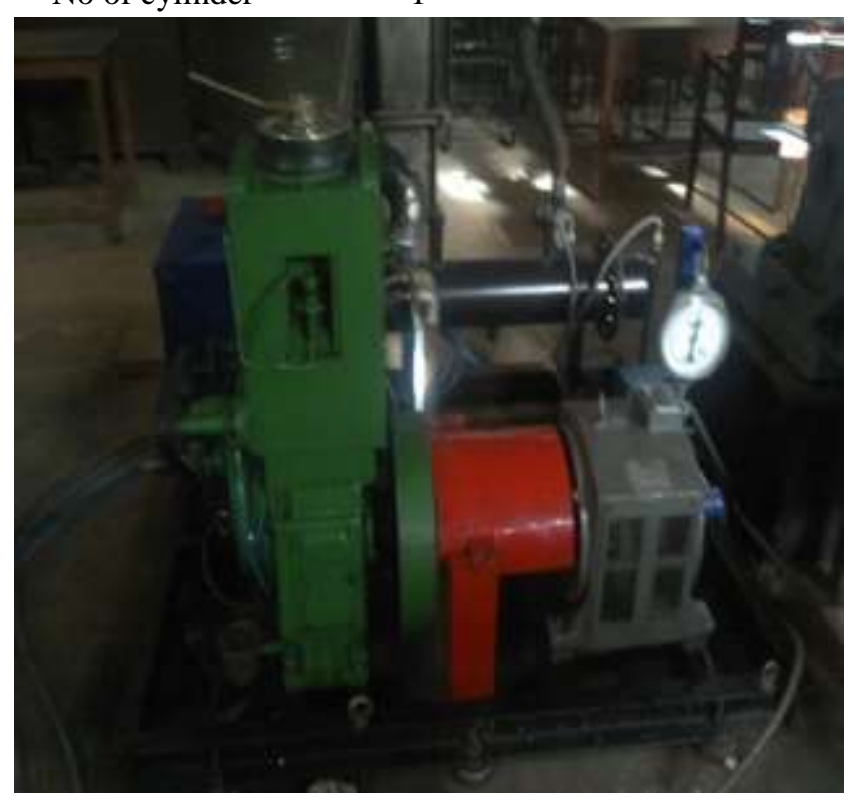

Fig. 1: Variable compression ratio diesel engine test rig experimental setup

\section{A. Experimental procedure}

The experiment is carried out on a single cylinder four stroke variable compression ratio vertical diesel engine test rig which has coupled to eddy current dynamometer.

$>$ Initially the engine was started by manual cranking in proper direction and the decompression lever is used for easy cranking.

$>$ The engine is allowed to run to attain the steady state.

$>$ Set the engine to a particular compression ratio.

$>$ Apply various load and note down the time taken for 10CC fuel consumption. 
$>$ Repeat the experiment for various compression ratios and corresponding readings are noted.

The following engine tests were performed in single cylinder variable compression ratio diesel engine test rig with diesel, and calophylluminophyllum methyl ester blended with diesel for various concentrations and finds the performance and Emission characteristic is studied.

The best performance was obtained for IC engine using diesel blend at $25 \%$ of bio-diesel and $75 \%$ of diesel.

Thus the tests are carried out for varying the compression ratios (14:1 to $18: 1)$ and various blend concentrations as follows.

$25 \%$ of calophylluminophyllum methyl ester $+75 \%$ of diesel.

B. Performance curves
The following performance curves were plotted using the values obtained

$>$ Load VsSpecific Fuel Consumptions (SFC)

$>$ Load Vs Brake Thermal Efficiency

$>$ Load Vs Mechanical Efficiency

\section{EXPERIMENTAL RESULTS AND DISCUSSION}

The performance tests are carried out on variable compression ratio (VCR) engine under different compression ratio (C.R) and loads using Diesel as fuel and the results are tabulated in the Table II.

The performance tests are carried out on variable compression ratio (VCR) engine under different compression ratio (C.R) and loads using $25 \%$ honne oil diesel blend as fuel and the results are tabulated in the Table III.

Table II: Performance observations for 100\% diesel

\begin{tabular}{|c|c|c|c|c|c|c|c|c|}
\hline C.R & LOA & B.P & TFC & SFC & Meff & ITE & BTE & IP \\
\hline & $\mathbf{K g}$ & $\mathbf{K W}$ & $\mathbf{K g} / \mathbf{h r}$ & $\mathbf{K g} / \mathbf{K W}-\mathbf{h r}$ & $\mathbf{\%}$ & $\mathbf{\%}$ & $\mathbf{\%}$ & $\mathbf{K W}$ \\
\hline $14: 1$ & 1 & 0.3151 & 0.4788 & 1.5194 & 22.270 & 24.059 & 5.3580 & 1.4151 \\
\hline $14: 1$ & 2 & 0.6238 & 0.6156 & 0.9868 & 36.190 & 22.794 & 8.2495 & 1.7238 \\
\hline $14: 1$ & 4 & 1.2276 & 0.7358 & 0.5993 & 52.741 & 25.753 & 13.582 & 2.3271 \\
\hline $14: 1$ & 6 & 1.8365 & 1.005 & 0.5475 & 62.54 & 23.774 & 14.868 & 2.9365 \\
\hline $15: 1$ & 1 & 0.3173 & 0.464 & 1.4624 & 19.382 & 28.720 & 5.5669 & 1.6373 \\
\hline $15: 1$ & 2 & 0.6238 & 0.5801 & 0.9299 & 32.094 & 27.277 & 8.7545 & 1.9438 \\
\hline $15: 1$ & 4 & 1.2356 & 0.7358 & 0.5954 & 48.350 & 28.276 & 13.671 & 2.5556 \\
\hline $15: 1$ & 6 & 1.8378 & 0.9427 & 0.5129 & 58.198 & 27.269 & 15.870 & 3.1578 \\
\hline $16: 1$ & 1 & 0.3183 & 0.4713 & 1.4805 & 19.794 & 27.778 & 5.4986 & 1.6083 \\
\hline $16: 1$ & 2 & 0.6254 & 0.5915 & 0.9457 & 32.654 & 26.362 & 8.6083 & 1.9154 \\
\hline $16: 1$ & 4 & 1.2316 & 0.7735 & 0.6280 & 48.842 & 26.539 & 12.962 & 2.5216 \\
\hline $16: 1$ & 6 & 1.8414 & 0.9731 & 0.5284 & 58.804 & 26.196 & 15.404 & 3.1314 \\
\hline $17: 1$ & 1 & 0.3173 & 0.4132 & 1.3021 & 22.711 & 27.527 & 6.2520 & 1.3973 \\
\hline $17: 1$ & 2 & 0.6254 & 0.5801 & 0.9275 & 36.674 & 23.932 & 8.7771 & 1.7054 \\
\hline $17: 1$ & 4 & 1.2372 & 0.7938 & 0.6416 & 53.393 & 23.762 & 12.687 & 2.3172 \\
\hline $17: 1$ & 6 & 1.8390 & 1.0056 & 0.5468 & 63.001 & 23.631 & 14.888 & 2.9190 \\
\hline $18: 1$ & 1 & 0.3183 & 0.4022 & 1.2634 & 22.931 & 28.099 & 6.4437 & 1.3883 \\
\hline $18: 1$ & 2 & 0.6278 & 0.5485 & 0.8735 & 36.980 & 25.200 & 9.3194 & 1.6978 \\
\hline $18: 1$ & 4 & 1.2396 & 0.7182 & 0.5794 & 53.673 & 26.178 & 14.050 & 2.3096 \\
\hline $18: 1$ & 6 & 1.8378 & 0.9141 & 0.4974 & 63.202 & 25.895 & 16.36 & 2.9078 \\
\hline
\end{tabular}

Table III: Performance observations for 25\% of Calophylluminophyllum $+75 \%$ diesel

\begin{tabular}{|c|c|c|c|c|c|c|c|c|}
\hline C.R & LOAD & B.P & TFC & SFC & Meff & ITE & BTE & IP \\
\hline & Kg & KW & Kg/hr & Kg/KW-hr & \% & \% & \% & KW \\
\hline $14: 1$ & 1 & 0.3149 & 0.4502 & 1.4296 & 23.4174 & 27.4106 & 6.4188 & 1.3449 \\
\hline $14: 1$ & 2 & 0.6254 & 0.5746 & 0.9186 & 37.7824 & 26.4375 & 9.9887 & 1.6554 \\
\hline $14: 1$ & 4 & 1.2235 & 0.7015 & 0.5733 & 54.2952 & 29.476 & 16.004 & 2.2535 \\
\hline $14: 1$ & 6 & 1.830 & 0.9577 & 0.5231 & 63.9930 & 27.4093 & 17.5401 & 2.860 \\
\hline $15: 1$ & 1 & 0.3163 & 0.4404 & 1.3920 & 24.7863 & 26.5951 & 6.5919 & 1.2763 \\
\hline $15: 1$ & 2 & 0.6198 & 0.5485 & 0.8849 & 39.2346 & 26.4311 & 10.370 & 1.5798 \\
\hline $15: 1$ & 4 & 1.2343 & 0.7015 & 0.5681 & 56.2610 & 28.7087 & 16.151 & 2.1948 \\
\hline $15: 1$ & 6 & 1.840 & 0.942 & 0.5123 & 65.7169 & 27.2571 & 17.912 & 2.800 \\
\hline $16: 1$ & 1 & 0.3171 & 0.4372 & 1.3785 & 25.4310 & 26.176 & 6.6569 & 1.2471 \\
\hline
\end{tabular}




\begin{tabular}{|c|c|c|c|c|c|c|c|c|}
\hline $16: 1$ & 2 & 0.6250 & 0.5485 & 0.8775 & 40.1959 & 26.0167 & 10.457 & 1.5550 \\
\hline $16: 1$ & 4 & 1.2340 & 0.7015 & 0.5685 & 57.0251 & 28.3057 & 16.141 & 2.1640 \\
\hline $16: 1$ & 6 & 1.8359 & 0.9282 & 0.5054 & 66.3700 & 27.3386 & 18.1446 & 2.765 \\
\hline $17: 1$ & 1 & 0.3171 & 0.4249 & 1.3396 & 26.0578 & 26.2873 & 6.8492 & 1.2171 \\
\hline $17: 1$ & 2 & 0.6238 & 0.5485 & 0.8792 & 40.9399 & 25.4946 & 10.437 & 1.5238 \\
\hline $17: 1$ & 4 & 1.2364 & 0.6935 & 0.5603 & 57.8744 & 28.2699 & 16.3610 & 2.1364 \\
\hline $17: 1$ & 6 & 1.8378 & 0.942 & 0.51297 & 67.1269 & 26.6495 & 17.8890 & 2.7378 \\
\hline $18: 1$ & 1 & 0.3165 & 0.3969 & 1.2539 & 21.5854 & 33.9041 & 7.31835 & 1.4665 \\
\hline $18: 1$ & 2 & 0.6254 & 0.5535 & 0.8849 & 36.4609 & 28.4393 & 10.3692 & 1.7154 \\
\hline $18: 1$ & 4 & 1.2316 & 0.6935 & 0.5630 & 53.0504 & 30.7200 & 16.2974 & 2.3216 \\
\hline $18: 1$ & 6 & 1.8358 & 0.8619 & 0.4696 & 62.7400 & 31.1450 & 19.5404 & 2.9253 \\
\hline
\end{tabular}

A. Performance curves for $25 \%$ honne oil and $75 \%$ diesel blend.

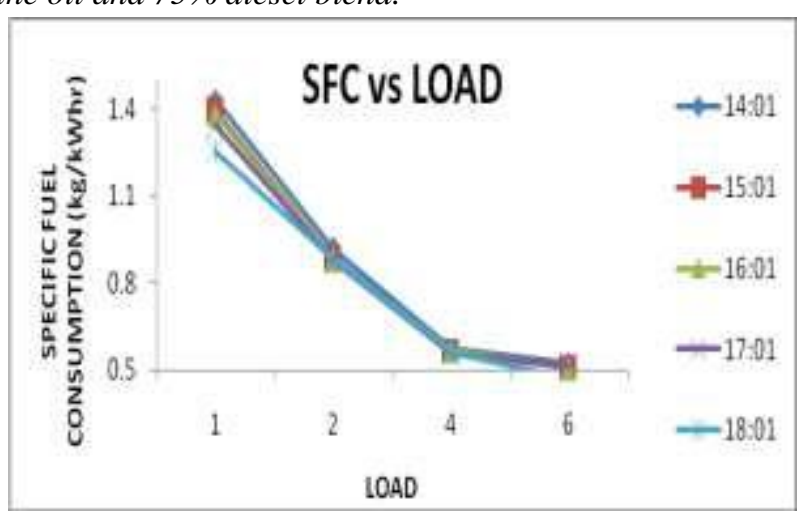

Fig. 2: Specific fuel consumption Vs Load

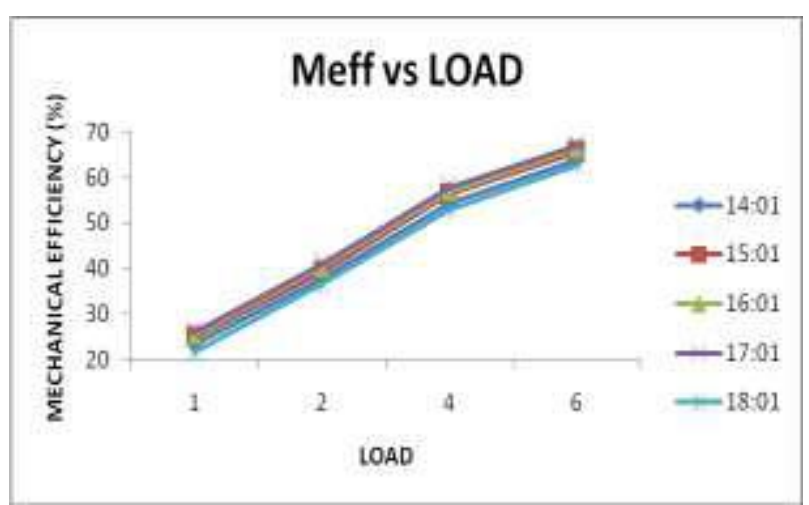

Fig. 3: Mechanical Efficiency Vs Load

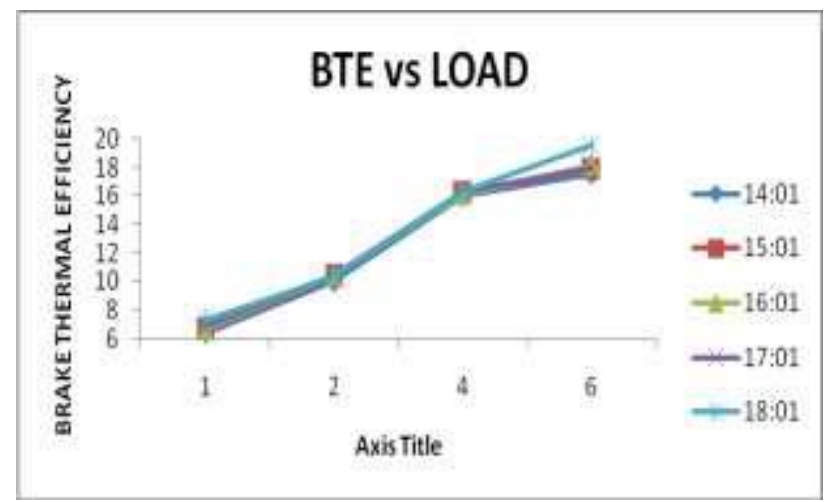

Fig. 4: Brake Thermal Efficiency Vs Load 


\section{B. Summary}

Based on the experimental data and the graphs were drawn for the different compression ratio and load with SFC, mechanical efficiency and brake thermal efficiency.The Fig 2, 3 and 4 shows that the SFC is almostequal for all the compression ratio. But the mechanical and brake thermal efficiency are more for the compression ratio of 18:1 than other values.

\section{ARTIFICIAL NEURAL NETWORK}

The first and arguably most simple type of artificial neural network is the feed neural network. Information are moves in only one direction forwards in this network: Data goes through the hidden nodes (if any) and to the output nodes from the input nodes. There are no cycles and loops in this network. Feed forward networks can be constructed from different types of units, e.g. binary McCulloch-Pitts neurons, the simplest example being the preception. Continuous neurons, frequently with sigmoidal activation, are used in the context of the back propagation of error.

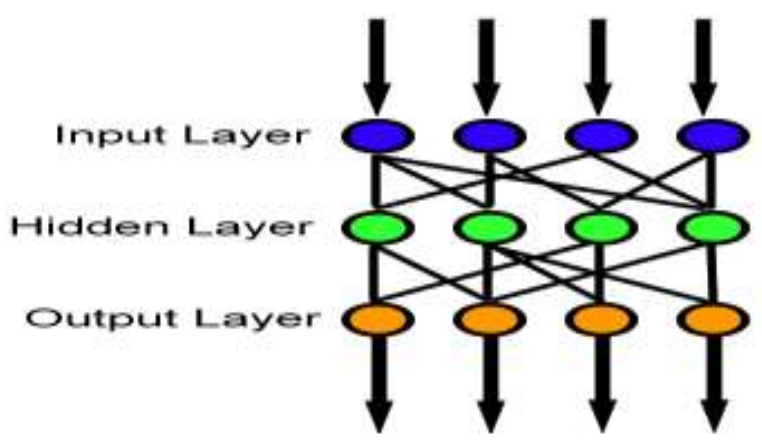

Fig.5: Simple feed forward back propagation network

In the model, $80 \%$ of the data set was randomly assigned as the training set, while the remaining $20 \%$ of the data are put aside for prediction and validation. From all of the trained networks, any ones could provide this condition, from which the simplest network was chosen to have a more precise investigation into the model. The correlation between the predicted values by the ANN model and the measured values resulted from experimental tests are very high.

\section{A. Prediction output responses using ANN}

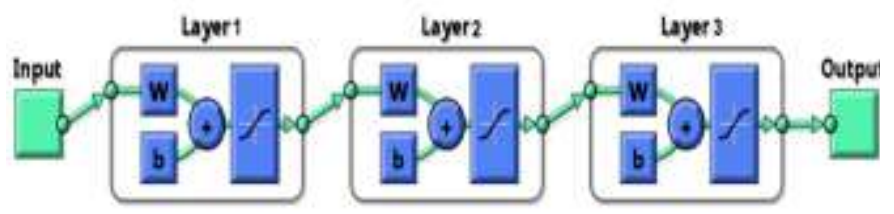

Table IV: Artificial Neural Network

\begin{tabular}{|c|c|}
\hline Output responses & ANN \\
\hline Brake power & $2-3-2-1$ \\
\hline
\end{tabular}

\begin{tabular}{|c|c|}
\hline SFC & $2-2-3-1$ \\
\hline Mechanical efficiency & $2-2-2-1$ \\
\hline
\end{tabular}

The training algorithm of Feed Forward Back-Propagation isselected for predicting engine parameters. The input response is selected as Compression Ratio and Load also Speed and volume of fuel consumed are taken as constant and the outputs are tabulated in Table $\mathrm{V}$

Table.V: Comparison experimental and predicted values of Brake Power

\begin{tabular}{|c|c|c|c|c|}
\hline \multirow{2}{*}{ C.R } & LOAD & \multicolumn{2}{|c|}{ BRAKE POWER (KW) } & \multirow{2}{*}{$\begin{array}{c}\text { of } \\
\text { error }\end{array}$} \\
\cline { 2 - 4 } & $\mathrm{Kg}$ & $\begin{array}{c}\text { EXPERIMENTAL } \\
\text { VALUES }\end{array}$ & $\begin{array}{c}\text { PREDICTED } \\
\text { VALUE }\end{array}$ & \\
\hline $14: 01$ & 1 & 0.3149 & 0.2952 & 6.26 \\
\hline $14: 01$ & 2 & 0.6254 & 0.6056 & 3.17 \\
\hline $14: 01$ & 4 & 1.2235 & 1.2041 & 1.59 \\
\hline $14: 01$ & 6 & 1.83 & 1.8102 & 1.08 \\
\hline $15: 01$ & 1 & 0.3163 & 0.2965 & 6.26 \\
\hline $15: 01$ & 2 & 0.6198 & 0.6005 & 3.11 \\
\hline $15: 01$ & 4 & 1.2343 & 1.2145 & 1.60 \\
\hline $15: 01$ & 6 & 1.84 & 1.8202 & 1.08 \\
\hline $16: 01$ & 1 & 0.3171 & 0.2973 & 6.24 \\
\hline $16: 01$ & 2 & 0.625 & 0.6052 & 3.17 \\
\hline $16: 01$ & 4 & 1.234 & 1.2142 & 1.60 \\
\hline $16: 01$ & 6 & 1.8359 & 1.8161 & 1.08 \\
\hline $17: 01$ & 1 & 0.3171 & 0.2973 & 6.24 \\
\hline $17: 01$ & 2 & 0.6238 & 0.604 & 3.17 \\
\hline $17: 01$ & 4 & 1.2364 & 1.2166 & 1.60 \\
\hline $17: 01$ & 6 & 1.8378 & 1.818 & 1.08 \\
\hline $18: 01$ & 1 & 0.3165 & 0.2967 & 6.26 \\
\hline $18: 01$ & 2 & 0.6254 & 0.6056 & 3.17 \\
\hline $18: 01$ & 4 & 1.2316 & 1.2118 & 1.61 \\
\hline $18: 01$ & 6 & 1.8358 & 1.816 & 1.08 \\
\hline & & & & \\
\hline
\end{tabular}

The below Fig. 6 (a), (b), (c), (d), (e) shows that the predicted neural network (2-3-2-1) for brake power. It is seen that the predicted values are very close to the experimental results and the maximum error is $6.26 \%$.

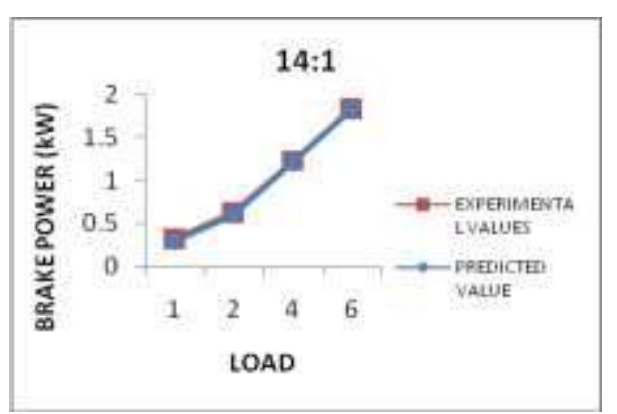

(a) 


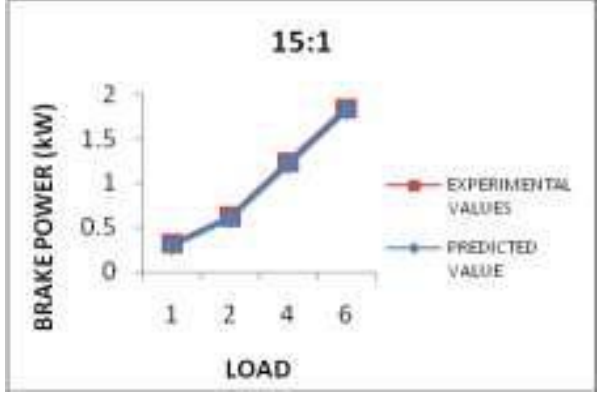

(b)

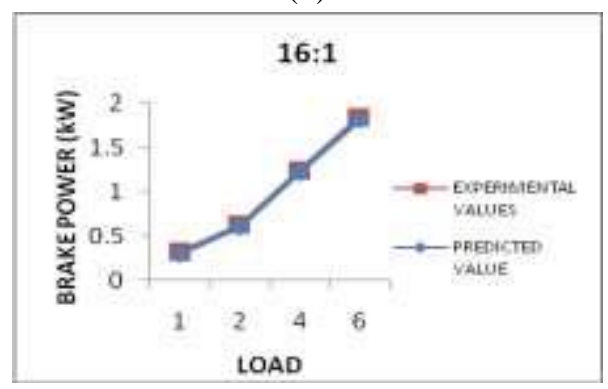

(c)

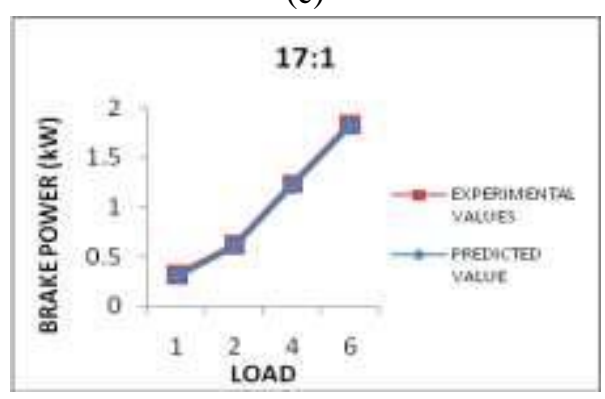

(d)

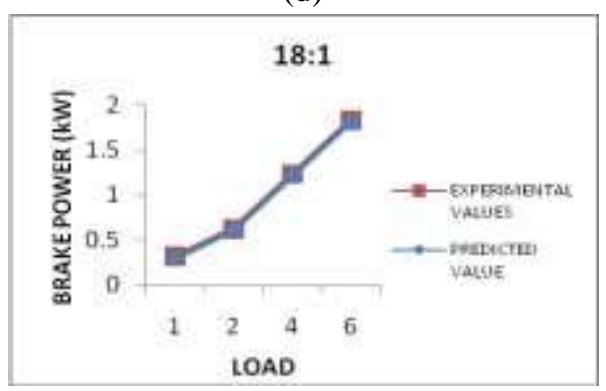

(e)

Fig. 6: Comparison of Predicted and Experimental Values of brake power

Then again the input response is selected as Compression Ratio and Load also Speed and volume of fuel consumed are taken as constant. Output response is Specific fuel consumption and it is tabulated in Table VI
Table VI: Comparison experimental and predicted values of Specific Fuel Consumption

\begin{tabular}{|c|c|c|c|c|}
\hline \multirow{2}{*}{ C.R } & \multirow{2}{*}{ LOAD } & \multicolumn{2}{|c|}{$\begin{array}{c}\text { SPECIFIC FUEL } \\
\text { CONSUMPTION }(\mathrm{kg} / \mathrm{kWhr})\end{array}$} & \multirow{2}{*}{$\begin{array}{c}\text { of } \\
\text { error }\end{array}$} \\
\cline { 2 - 4 } & $\mathrm{Kg}$ & $\begin{array}{c}\text { EXPERIMENTAL } \\
\text { VALUES }\end{array}$ & $\begin{array}{c}\text { PREDICTED } \\
\text { VALUE }\end{array}$ & \\
\hline $14: 01$ & 1 & 1.4296 & 1.4093 & 1.42 \\
\hline $14: 01$ & 2 & 0.9186 & 0.8988 & 2.16 \\
\hline $14: 01$ & 4 & 0.5733 & 0.5539 & 3.38 \\
\hline $14: 01$ & 6 & 0.5231 & 0.5033 & 3.79 \\
\hline $15: 01$ & 1 & 1.392 & 1.3722 & 1.42 \\
\hline $15: 01$ & 2 & 0.8849 & 0.8656 & 2.18 \\
\hline $15: 01$ & 4 & 0.5681 & 0.5483 & 3.49 \\
\hline $15: 01$ & 6 & 0.5123 & 0.4925 & 3.86 \\
\hline $16: 01$ & 1 & 1.3785 & 1.3587 & 1.44 \\
\hline $16: 01$ & 2 & 0.8775 & 0.8577 & 2.26 \\
\hline $16: 01$ & 4 & 0.5685 & 0.5487 & 3.48 \\
\hline
\end{tabular}

Table VI contd.: Comparison experimental and predicted values of Specific Fuel Consumption

\begin{tabular}{|c|c|c|c|c|}
\hline \multirow{2}{*}{ C.R } & LOAD & $\begin{array}{c}\text { SPECIFIC FUEL } \\
\text { CONSUMPTION } \\
(\mathrm{kg} / \mathrm{kWhr})\end{array}$ & LOAD & \% of \\
\cline { 2 - 5 } & $\mathrm{kg}$ & $\begin{array}{c}\text { EXPERIMENTAL } \\
\text { VALUES }\end{array}$ & $\mathrm{kg}$ & \\
\hline $16: 01$ & 6 & 0.5054 & 0.4856 & 3.92 \\
\hline $17: 01$ & 1 & 1.3396 & 1.3198 & 1.48 \\
\hline $17: 01$ & 2 & 0.8792 & 0.8594 & 2.25 \\
\hline $17: 01$ & 4 & 0.5603 & 0.5405 & 3.53 \\
\hline $17: 01$ & 6 & 0.51297 & 0.49317 & 3.86 \\
\hline $18: 01$ & 1 & 1.2539 & 1.2341 & 1.58 \\
\hline $18: 01$ & 2 & 0.8849 & 0.8651 & 2.24 \\
\hline $18: 01$ & 4 & 0.563 & 0.5432 & 3.52 \\
\hline $18: 01$ & 6 & 0.4696 & 0.4498 & 4.22 \\
\hline
\end{tabular}

The below Fig. 7 (a), (b), (c), (d), (e) shows that the predicted neural network (2-3-2-1) for SFC.It is seen that the predicted values are very close to the experimental results and the maximum error is $3.86 \%$.

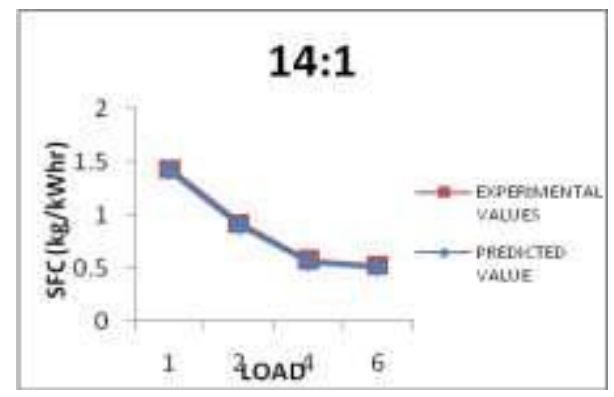

(a) 


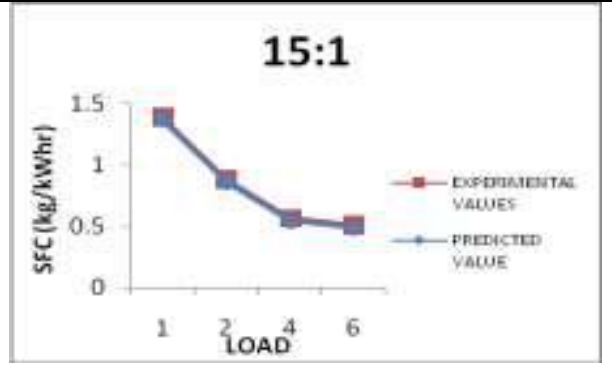

(b)

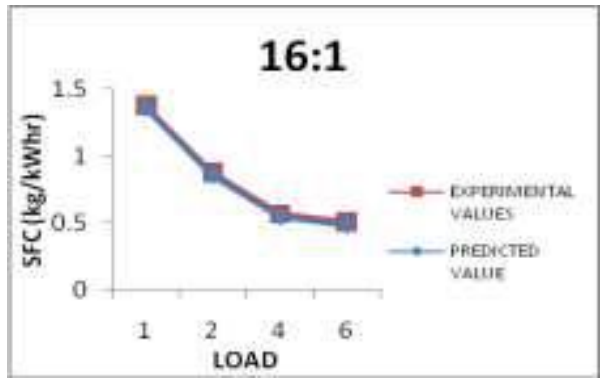

(c)

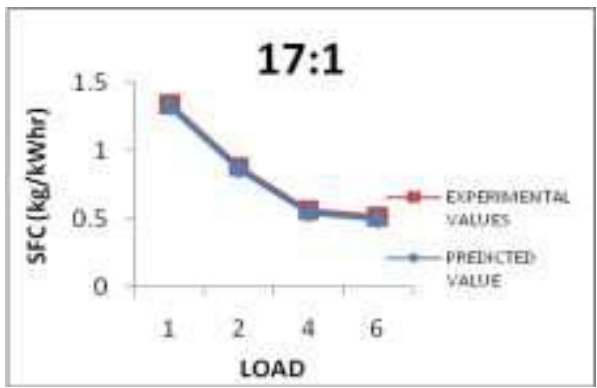

(d)

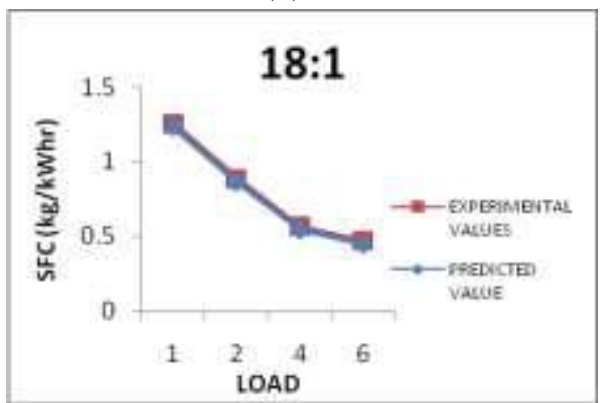

(e)

Fig. 7: Comparison of Predicted and Experimental Values of SFC

Then again input response is selected as Compression Ratio and Load also Speed and volume of fuel consumed are taken as constant. Output response is Mechanical Efficiency and the outputs are tabulated in Table VII
Table VII: Comparison experimental and predicted values of brake thermal efficiency

\begin{tabular}{|c|c|c|c|c|}
\hline C.R & LOAD & \multicolumn{2}{|c|}{$\begin{array}{c}\text { MECHANICAL EFFICIENCY } \\
(\%)\end{array}$} & $\begin{array}{c}\% \text { of } \\
\text { error }\end{array}$ \\
\hline & $\mathrm{kg}$ & $\begin{array}{c}\text { EXPERIMENTAL } \\
\text { VALUES }\end{array}$ & $\begin{array}{c}\text { PREDICTED } \\
\text { VALUE }\end{array}$ & \\
\hline $14: 01$ & 1 & 23.4174 & 22.4644 & 4.07 \\
\hline $14: 01$ & 2 & 37.7824 & 36.8294 & 2.52 \\
\hline $14: 01$ & 4 & 54.2952 & 53.3422 & 1.76 \\
\hline $14: 01$ & 6 & 63.993 & 63.04 & 1.49 \\
\hline $15: 01$ & 1 & 24.7863 & 23.8333 & 3.84 \\
\hline $15: 01$ & 2 & 39.2346 & 38.2816 & 2.43 \\
\hline $15: 01$ & 4 & 56.261 & 55.308 & 1.69 \\
\hline $15: 01$ & 6 & 65.7169 & 64.7639 & 1.45 \\
\hline $16: 01$ & 1 & 25.431 & 24.478 & 3.75 \\
\hline $16: 01$ & 2 & 40.1959 & 39.2429 & 2.37 \\
\hline $16: 01$ & 4 & 57.0251 & 56.0721 & 1.67 \\
\hline $16: 01$ & 6 & 66.37 & 65.417 & 1.44 \\
\hline $17: 01$ & 1 & 26.0578 & 25.1048 & 3.66 \\
\hline $17: 01$ & 2 & 40.9399 & 39.9869 & 2.33 \\
\hline $17: 01$ & 4 & 57.8744 & 56.9214 & 1.65 \\
\hline $17: 01$ & 6 & 67.1269 & 66.1739 & 1.42 \\
\hline $18: 01$ & 1 & 21.5854 & 20.6324 & 4.42 \\
\hline $18: 01$ & 2 & 36.4609 & 35.5079 & 2.61 \\
\hline $18: 01$ & 4 & 53.0504 & 52.0974 & 1.80 \\
\hline $18: 01$ & 6 & 62.74 & 61.787 & 1.52 \\
\hline & & & & \\
\hline
\end{tabular}

The below Fig. 8 (a), (b), (c), (d), (e) shows that the predicted neural network (2-3-2-1) for mechanical efficiency. The values are more accurate with the maximum error of $3.84 \%$..

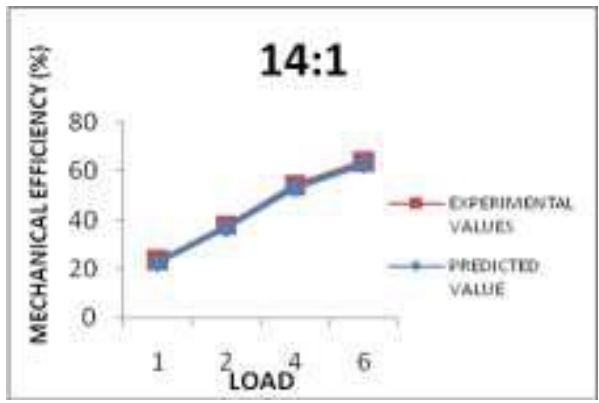

(a)

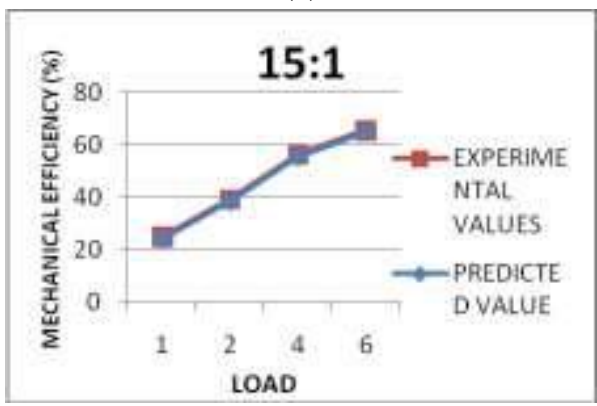

(b) 


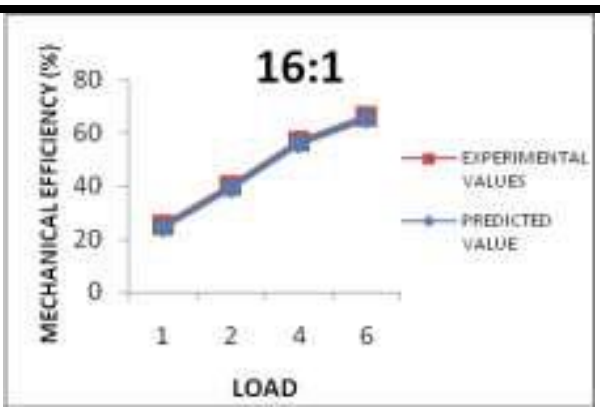

(c)

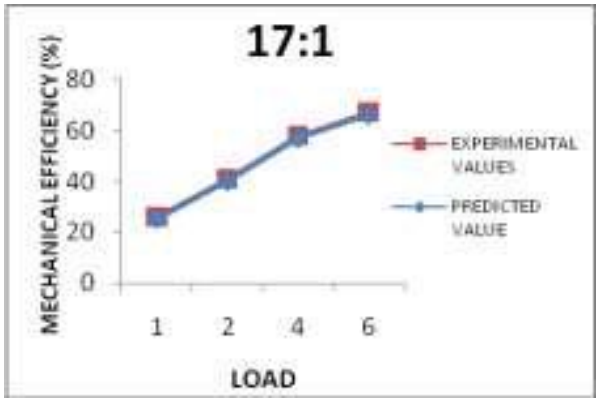

(d)

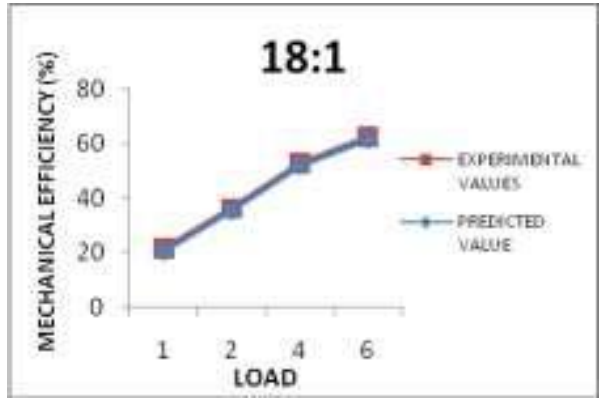

(e)

Fig.8: Comparison of Predicted and Experimental Values of Mechanical Efficiency.

\section{CONCLUSION}

The performance test on VCR engine is carried out for the engine fueled with $25 \%$ biodiesel blend and neat diesel. The experimental results of both the fuels are compared. Thus it is understood thatthe $25 \%$ biodiesel blend produces better performance than base fuel at the compression ratio of $18: 1$

The training algorithm of Feed Forward Back-Propagation is selected for predicting engine parameters. The input responses selected are Compression Ratio and Load by taking speed as constant. Then, the ANN results are validated with experimental results and found satisfactory. Thus it can be concluded that the training algorithm of feed forward back-propagation is sufficient in predicting engine performance parameters.

\section{REFERENCES}

[1] Nilesh. M, Sujit. K, Vinay. K and Tausif Mulla, Study of performance characteristics of variable compression ratio diesel engine using ethanol blends with diesel, International Journal of Engineering Science and Technology Vol. 4, No.6, pp.2784-2795, 2012

[2] Sarala. R,Rajendran. M andSutharson B, Exhaust emission analysis using nakthamala oil biodiesel fuel in a c.i engine with ann, International Journal of Research in Environmental Science and Technology, Vol.2, No.2, pp.48-53, 2012.

[3] Balajiganesh. N and Chandra Mohan Reddy. B, Optimization of C.I Engine Parameters Using Artificial Neural, International Journal of Mechanical and Industrial Engineering, Vol.1, No.2, pp.76-82, 2011.

[4] Deepanraj. B, Dhanesh. C, Senthil. R andKannan. M, Use of Palm oil Biodiesel Blends as a Fuel for Compression Ignition Engine, American Journal of Applied Sciences Vol.8,No.11, pp.1154-1158, 2011.

[5] Venkanna.B.K andVenkataramana Reddy.C, Performance, emission and combustion characteristics of direct injection diesel engine running on calophylluminophyllumlinn oil (honne oil), International Journal of Agricultural and Biological Engineering, , Vol.4 No.1, pp.1-9, 2011.

[6] Seshaiah. N, Efficiency and exhaust gas analysis of variable compression ratio spark ignition engine fuelled with alternative fuels", international journal of energy and environment, Vol.1, No.5, pp.861-870, 2010.

[7] Shivakumar, SrinivasPai. P, Shrinivasarao.B andSamaga. B. S., "Performance And Emissioncharacteristics of a 4 Stroke C.I. Engine Operated On Honge Methyl Ester Using Artificial Neural Network, ARPN Journal of Engineering and Applied Sciences, Vol.5,No.6, pp.83-94, 2010.

[8] Anand. R, Kannan. G, Rajasekhar Reddy. K and Velmathi. S, The performance and emissions of a variable compression ratio diesel engine fuelled with bio-diesel from cotton seed oil, ARPN Journal of Engineering and Applied Sciences, Vol.4, No.9, pp.7287, 2009.

[9] Ratnakara Rao. V, RamachandraRaju and Muralidhara Rao. M, Optimising the compressionratio of diesel fuelled C.I engine, ARPN Journal of Engineering and Applied Sciences, Vol.3,no.2,2008 